\title{
Prevalent posttraumatic stress disorder among emergency department personnel: rapid systematic review
}

\author{
Diane I. N. Trudgill (1) ${ }^{1 凶}$, Kevin M. Gorey ${ }^{1}$ \& Elizabeth A. Donnelly (i) ${ }^{1}$
}

This research review synthesized the evidence on the prevalence of posttraumatic stress disorder among emergency department personnel in Canada and the USA. No previous such synthesis, specific to this crucial aspect of North American health care had previously been published. Broad keyword searches of interdisciplinary research databases, both peerreviewed and grey, retrieved 10 surveys published between 1996 and 2019. Their outcomes were synthesized with sample-weighted, pooled analyses. The most significant review finding was that one of every five such emergency care personnel met posttraumatic stress disorder diagnostic criteria; $18.6 \%$ (95\% confidence interval 16.9, 20.4). However, this synthesis of generally small, nonprobability surveys with high nonparticipation rates, could only suggest that the prevalence of posttraumatic stress disorder is perhaps nearly two-fold greater among emergency department nurses (25.8\%) than physicians (15.6\%). Additionally, it seems that gender (being a woman) may play an important role in the relatively greater risk of nurses. Better controlled, more powerful probability surveys that examine the profession by gender interaction, are needed to affirm (or refute) these synthetic findings. Qualitative inquiries that tap into the key informing experiences of diverse emergency department personnel are also needed to best plan and implement their preventive and therapeutic care.

\section{Introduction}

mergency departments (ED) are intense, highly stressful workplaces. The nurses and - physicians who work there routinely witness much human suffering. For example, they care for patients with lacerations and broken bones, life threatening conditions, such as heart attacks and strokes, burn victims as well as victims of motor vehicle accidents and gun violence. Caring for patients at end-of-life and witnessing death, including the unexpected deaths of children, is also routine (Laposa and Alden, 2003; Schwab et al., 2016). Furthermore, emergency nurses are also frequent victims of verbal and physical abuse. In fact, ED nurses have the highest physical assault rate of any nursing specialty (Crilly et al., 2004; Needham et al., 2005). Moreover, ED staff must often go from one traumatic event to another, without time to process the resultant stresses or to engage in self-care (Schwab et al., 2016). Overcrowding of EDs in North America likely further compound the challenge of and stress associated with the provision of high-quality emergency care. For a number of reasons, ranging from physician and nursing 
shortages to insurance inadequacies, ED staff in Canada and the USA must increasingly also care for waiting rooms full of patients with non-urgent conditions (Butun et al., 2019; Morley et al., 2018). In short, EDs are places where indirect and direct traumas, acute and chronic stressors are prevalent. It seems likely that such exposures increase the risk of developing posttraumatic stress disorder (PTSD; Adriaenssens et al., 2012; Kilpatrick et al., 2013).

PTSD is well known to be comorbidly associated with other serious mental health challenges such as alcohol dependence, drug abuse, anxiety, depression, and suicide among diverse health care workers (Cottler et al., 2013; Schernhammer and Colditz, 2004). It has also been firmly established as an occupational hazard among first responders such as police officers and firefighters, paramedics/emergency medical personnel, nurses and physicians. Among them, PTSD is highly predictive of diminished quality of care, lost workdays, burnout and ultimately, high staff turnover (Adriaenssens et al., 2012; Carleton et al., 2018; Katsavouni et al., 2016; Ruitenburg et al., 2012; Slatten et al., 2011; van Bogaert et al., 2013). Despite their chronic exposure to traumatic events, little research has been focussed specifically on ED personnel. Given that other similar high-stress professions have high rates of PTSD, it may be possible that ED personnel are at a similarly elevated risk as the more studied first responding, rescue, disaster, or trauma care providers.

PTSD among emergency and intensive care workers: review of previous reviews. Four systematic reviews, two with metaanalytic components, synthesized the evidence on PTSD prevalence among ambulance and hospital emergency department or intensive care providers (Berger et al., 2012; Donnelly and Siebert, 2009; Petrie et al., 2018; Robertson and Perry, 2010). These populations are included for discussion here because of the analogous work they do, and the relative dearth of literature specifically examining ED staff. The reviews' synthetic PTSD prevalence estimates can be compared to those of the general adult populations of Canada (2.5\%) and the USA (4.0\%) and to general health care providers in North America (10\%; Kilpatrick et al., 2013; Robertson and Perry, 2010; van Ameringen et al., 2008). The synthetic findings of the nearly 100 studies reviewed provide an important heuristic insight into the risks incurred by those who do this crucial work. Police officers and firefighters seem to be at similar PTSD risk as health care workers, all at two to three-fold greater risk than other adults. Ambulance personnel were estimated to experience about twice the risk as other first responders, putting them at four to six-fold greater risk than, otherwise similar, general population counterparts (Petrie et al., 2018). And of all the groups, intensive care nurses were estimated to be at greatest risk of having PTSD. Approximately one of every four of them reported symptoms and experiences consistent with a PTSD diagnosis (Robertson and Perry, 2010). These reviews provided a valuable service, allowing knowledge users to understand the magnitude of the PTSD problem among emergency care providers, prehospital and hospital based. Such problem-definition is a necessary first step in planning preventive and therapeutic interventions.

Exploring the gender divide in emergency care. In responding to this study's central research question about the prevalence of PTSD among ED clinical staff, we will explore differences between nurses and physicians. As the majority of ED physicians remain men and nurses, women, in both Canada and the USA, such naturally points toward a hypothesized gender divide and the relative oppression of women (Hay et al., 2019). Syntheses of interrelated fields of practice have strongly suggested that professional status and gender matter very much. A systematic review of 28 studies of disaster workers found that nurses had consistently more adverse outcomes such as depression and PTSD than physicians (Naushad et al., 2019). While another systematic review of 40 studies and a meta-analysis of 25 studies of the general population and of health care workers, found that women were twice as likely to have been physically assaulted and diagnosed with anxiety disorders, depression or PTSD (Schernhammer and Colditz, 2004; Tolin and Foa, 2008). It has been theorized that because all women will have been traumatized more throughout their lives and that they will generally have less authority and so control in health care workplaces, including EDs, they will be at greater risk of developing mental health problems, including PTSD (Kerasiotis and Motta, 2004). This converges with the call of intersectionality theorists for more complex study of interlocking systems of oppression and privilege (Bowleg, 2012; Hulko, 2009). Understanding such more specific interactions might help tailor more specific preventive and therapeutic interventions in this field.

The current study synthesizes the evidence on the prevalence of PTSD among ED nurses, physicians, and trauma surgeons. This study's primary aim is to answer the foundational question of prevalence: Using the extant literature to generate a pooled estimate of PTSD, what is the prevalence among ED personnel? Additionally, in contrast to previously published reviews, this study will provide disaggregated ED-specific PTSD estimates. We hypothesize that the prevalence of PTSD among ED clinical staff in Canada and the USA will be statistically and practically significant, and secondly, we will explore the following two moderator hypotheses: PTSD will be more prevalent among nurses and women.

\section{Methods}

Selection of primary studies. The following published research databases were searched until March 31, 2020: Cumulative Index of Nursing \& Allied Health Literature (CINAHL) Complete, ProQuest Nursing \& Allied Health Database, PsycINFO, PubMed, Ovid MEDLINE, and Social Service Abstracts. The following grey literature databases were also searched to protect against publication bias: ProQuest Dissertations \& Theses Global, Conference Proceedings Citation Indexes-Science and Social Sciences \& Humanities and Google Scholar (de Smidt and Gorey, 1997; Grenier and Gorey, 1998). Search terms used were: (posttraumatic stress disorder or PTSD) and (emergency and (department or room) or ED or ER or trauma care) and (prevalence or incidence or occurrence or survey or cohort). These searches returned 479 unduplicated potential studies that were then assessed for the following inclusion criteria: (1) ED nurses and or physicians were included in the sample, (2) conducted in a highincome country (3) routine emergency care was assessed (studies of special circumstances such as natural disasters were excluded) and (4) PTSD prevalence rates were reported or calculable. Two reviewers independently searched for eligible studies and consensus decisions were reached after discussion. Ten studies met all criteria and were included in this research synthesis. They are denoted with an asterisk in the reference list.

Analysis of prevalence estimates. Each study provided one PTSD prevalence estimate, that is, the proportion of its sample so affected, for the pooled analysis. If not reported, 95\% confidence intervals (CI) were calculated around each PTSD estimate (Fleiss et al., 2003). Only one study reported separate estimates for nurses and physicians (Luftman et al., 2017). These two estimates were pooled so that that study would contribute one data point toward the main hypothesis test. As the 10 prevalence estimates from the 10 primary studies were all discrete, they were combined into a common 
Table 1 Posttraumatic stress disorder prevalence among emergency department personnel: Characteristics and outcomes of 10 surveys.

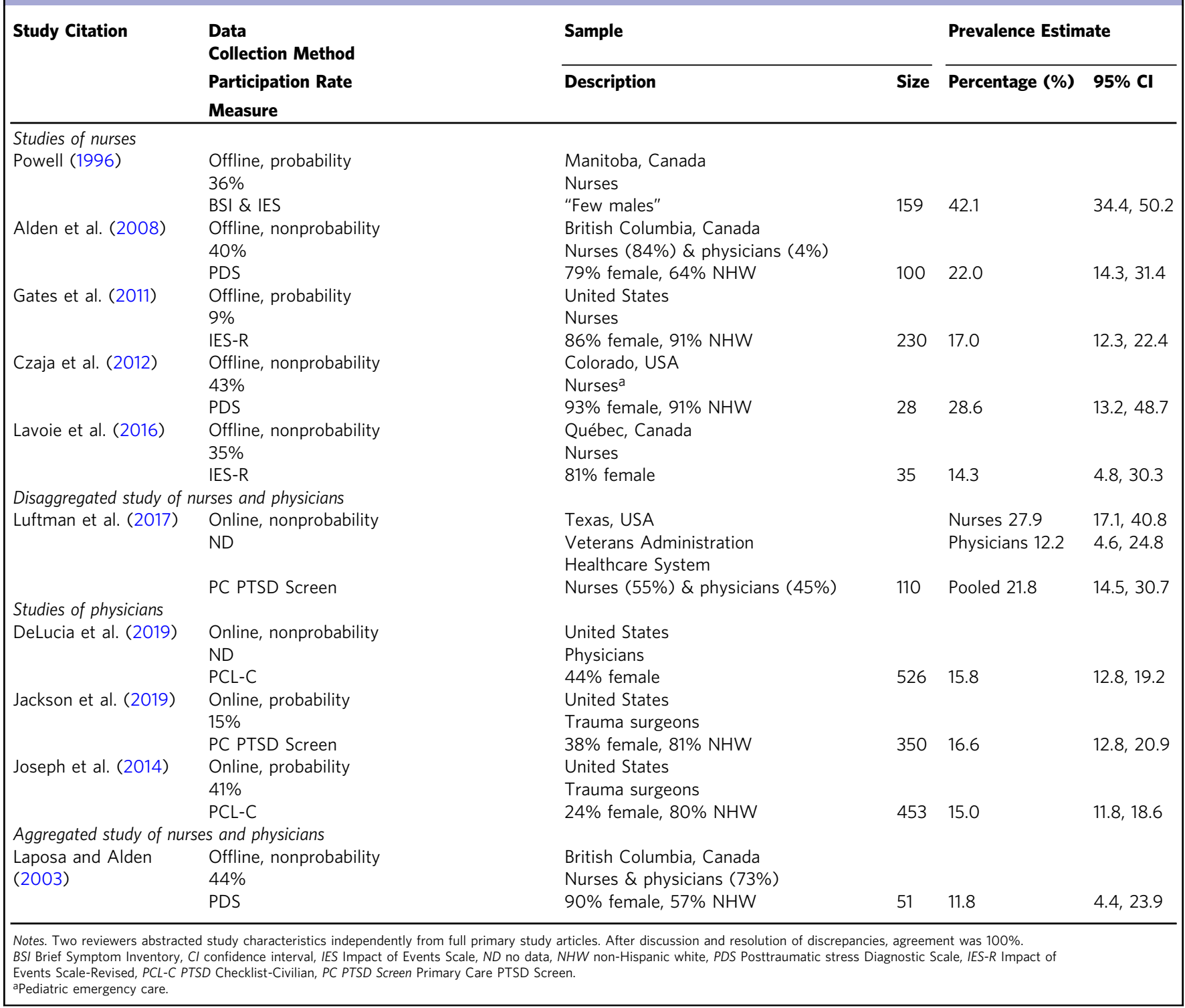

database, allowing for a powerful overall, sample-weighted pointestimate along with its 95\% CI (Cooper, 2017; Cooper and Patall, 2009). Chi-square $\left(\chi^{2}\right)$ statistics were used to test the moderator hypotheses: nurses versus physicians and women versus men. Review hypotheses were cross validated by two analysts.

\section{Results}

Sample description. Descriptive characteristics and outcomes of the 10 primary surveys are displayed in Table 1 . Accomplished in Canada (four studies) and the USA (6) over the past 25 years, they studied nurses (5), physicians (3), or both (2). The aggregated review sample of $2042 \mathrm{ED}$ clinical staff members was fairly evenly distributed on gender ( $52 \%$ women), while most were nonHispanic white people (80\%). The four study measures seemed psychometrically sound, with reliability coefficients in the $0.80-0.90$ range, and similar cut-off score-based criterion validities as their synthetic PTSD estimates did not differ significantly (Foa et al., 2016; Prins et al., 2016; Weiss, 2007; Wilkins et al., 2011). Otherwise, the studies seemed quite methodologically limited. The majority used nonprobability methods to sample relatively small numbers of participants (median $=135$; range $=28-526)$. Also, survey participation rates were quite low (median $=38 \%$; range $=9-44 \%)$. Finally, the 10 survey prevalence estimates that ranged from $11.8 \%$ to $42.1 \%$ (median $=16.8 \%$ ) were all minimally statistically significant at $p<0.05$.

Prevalence of PTSD among ED personnel. Sample-weighted, pooled analyses related to this study's hypotheses are displayed in Table 2. Support for the main hypothesis is seen in the table's top line. The pooled prevalence of PTSD among ED personnel was estimated to be $18.6 \%$ (95\% CI 16.9, 20.4). The pooled estimates of nine studies supported the moderator hypothesis that nurses are at nearly two-fold greater such PTSD risk (25.8\%) than physicians $(15.6 \%) ; \chi^{2}(1, N=1,991)=28.84, p<0.05$. Recall that one study provided an estimate for each group. It cross-validated greater PTSD burden among nurses (27.9\%) than physicians (12.2\%; Luftman et al., 2017): $\chi^{2}(1, N=110)=4.01, p<0.05$. The aggregated sample of nurses in the pooled comparison were predominantly women 
Table 2 Posttraumatic stress disorder prevalence moderated by participant and study characteristics.

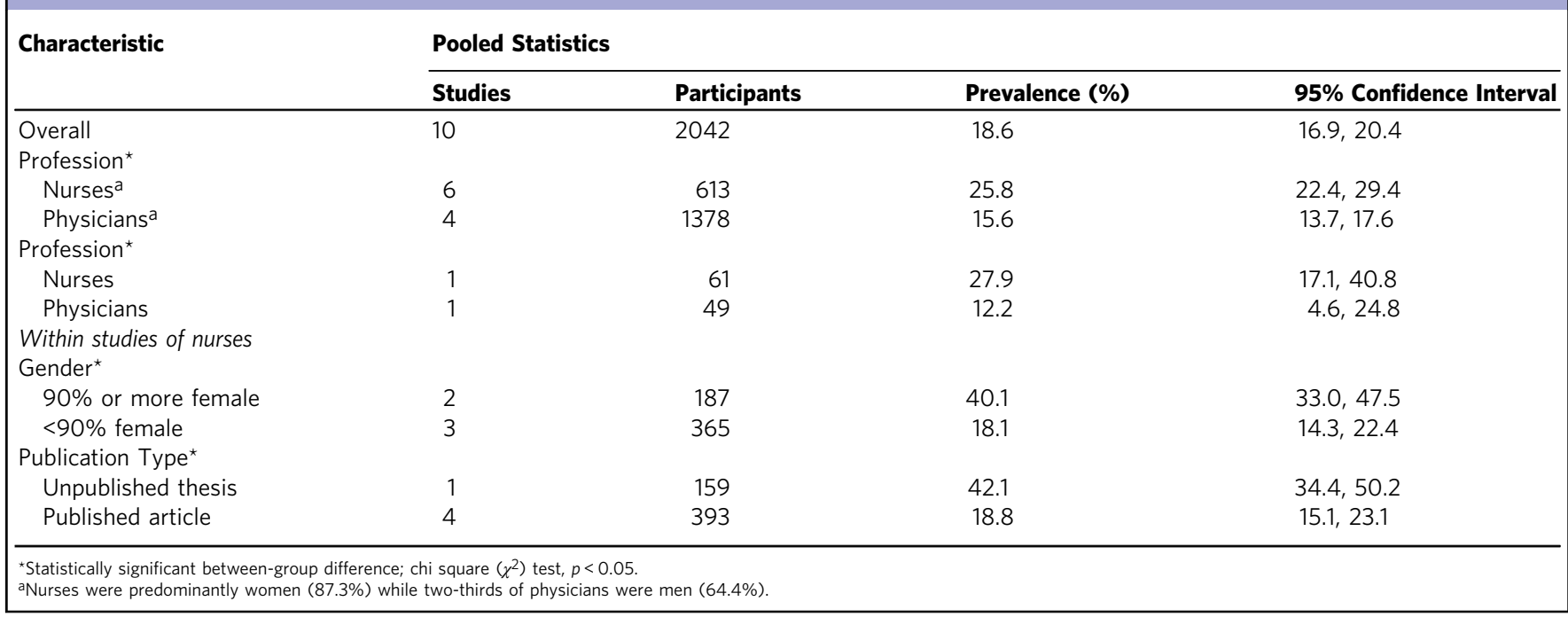

(87.3\%), while two-thirds of the physicians were men (64.4\%). Though consistent with expectations, it also means that the analysis on professional discipline was confounded by gender.

Modest support was found for the moderator hypothesis on gender. To gain an unconfounded view we tested the difference between women and men within pooled samples of nurses; there was not enough power to similarly analyze physicians. Pooled estimates of five studies supported the hypothesis that women (study samples $\geq 90 \%$ women) were much more likely to meet criteria for PTSD (40.1\%) than men (study samples $<90 \%$ women, $18.1 \%) ; \chi^{2}(1, N=552)=31.54, p<0.05$. Finally, moderations by all participant, study and contextual, temporal and geographic, characteristics were explored; only publication type was significant. The PTSD estimate of the unpublished thesis (42.1\%) was significantly larger than the estimate based on published articles $(18.8 \%) ; \chi^{2}(1, N=552)=32.34, p<0.05$.

Sensitivity analysis. One of the primary studies included in this review seems an outlier. The unpublished master's thesis was the earliest of this field's studies and reported its highest PTSD estimate (Powell, 1996). Some might argue for its exclusion. We think not as unpublished sources were explicitly searched as a means of controlling for potential publication bias. A sensitivity analysis excluding Powell's study found similar support for all three of this study's hypotheses. The overall PTSD estimate among ED personnel remained significant (16.6\%, 95\% CI 15.0, 18.4 ), differing by only $2 \%$ from the original estimate. The professional PTSD divide remained significant: nurses $(20.0 \%)$ versus physicians $(15.6 \%) ; \chi^{2}(1, N=1832)=4.84, p<0.05$. Finally, a nonsignificant trend in the hypothesized direction was still detected by gender: women $(28.6 \%)$ versus men $(18.1 \%) ; \chi^{2}$ $(1, N=393)=1.87, p=0.17$.

\section{Discussion}

This study is the first systematic synthesis of PTSD prevalence among the clinical staff of EDs. Its overall finding was the most significant. Consistent and precisely pooling the experience of more than 2000 nurse or physician participants of 10 surveys in Canada or the USA, it estimated that one of every five of them met the diagnostic criteria for PTSD (18.6\%, 95\% CI 16.9, 20.4). This estimate is nearly double that observed among first responders, including police officers, firefighters, paramedics, and general health care providers, and it is several times higher than estimates among general adult populations of Canada and the USA (Berger et al., 2012; Carleton et al., 2018; Donnelly and Siebert, 2009; Kilpatrick et al., 2013; Petrie et al., 2018; Robertson and Perry, 2010; van Ameringen et al., 2008). Though more equivocal for the lack of statistical power, this study suggested that the prevalence of PTSD is significantly greater among ED nurses than physicians, and that gender probably plays a role in such relatively greater risk among nursing staff. In fact, their risk (25.8\%, approximately one of every four ED nurses) was estimated to be about twice that of physicians (15.6\%, approximately one of every eight ED physicians). Applying this study's estimates to the emergency care populations of Canada and the USA, we estimate that more than 100,000 nurses and nearly 20,000 physicians are at risk of having a constellation of PTSD symptoms or a formal PTSD diagnosis (American Medical Association, 2019; Canadian Institutes of Health Information, 2019a, 2019b; U.S. Bureau of Labor Statistics, 2019). Clearly, these findings are of great public health and policy significance.

Potential limitations and future research needs. This area of research is not without its limitations. Perhaps most notably, the participation rates of all its primary studies were $<50 \%$, typically only about $33 \%$. Bias most assuredly intruded because of this, but what was its likely direction? Research has suggested that those who are most at-risk of serious mental health challenges are the least likely to participate in voluntary studies (Cheung et al., 2017). Also, the primary study samples likely did not include staff on sick leave, some of whom may have been off due to the effects of PTSD. It also seems conceivable that some ED nurses and physicians chose not to participate for fear of managers learning of their struggles and consequently damaging their careers (Powell, 1996). None of their experiences would have been captured in the primary studies nor in this synthesis. So, while it seems very likely that this field's research findings were biased by nonparticipation, its likely direction is clear. It probably operated such that this study's synthetic estimates of PTSD were underestimates of the truth.

Though its sampling frame included unpublished sources, this review's sample ultimately included only one unpublished study. One might wonder if publication bias could be a potent alternative explanation for its findings. This seems improbable for the following reason. The single unpublished study reported the largest prevalence estimate $(40.1 \%)$. This pattern is the opposite one would expect if publication bias, that is, a preference 
to publish significant findings, was potent; a sensitivity analysis that excluded this one outlying, unpublished study crossvalidated this synthetic study's main findings.

We were only able to tentatively explore the gender divide. The primary studies were limited in a number of interrelated ways that necessarily limited our synthesis. First, only one of the primary studies compared women and men on PTSD. Second, profession and gender comparisons were confounded in the remaining studies. Analytic samples of nurses were predominantly women (87\%) while two-thirds of physician samples were men (64\%), making it difficult to observe any unique risks associated with being a nurse versus those associated with being a woman. Consequently, our pooled analysis of gender relied on a rather gross proxy measure of gender: study samples were $<90$ or $90 \%$ or more female. Surely such analyses may have been residually confounded. Third, this field's studies were generally small, but the disaggregated samples of nurses $($ median $=100)$ were much smaller than those of physicians (median $=453$ ). Finally, a number of studies of nurses reported that they tested gender in a post hoc way and found it to be null. In our view, such inferences ought to be disregarded as they were essentially devoid of statistical power. For example, three such inferences were based upon quite small samples of between 26 and 46 participants (Czaja et al., 2012; Laposa and Alden, 2003; Lavoie et al., 2016). What may not be clear to the casual reader is that because these already small samples of nurses were predominantly women, their implied comparison groups of men were extremely small, ranging from only 2 to 7 men. No knowledge user would be able to confidently use such evidence in making any clinical or policy decision.

What seems clearly called for is a much more powerful, internally and externally valid knowledge base that could be produced by large national probability surveys. It ought to be statistically powered by ample samples of nurses and physicians, women and men in Canada and the USA sufficient to allow the detection of modest, but practically significant, between-group differences with confidence. For example, using standard statistical criteria, samples of at least 100 participants in each study group would be required to detect between-group PTSD prevalent differences of 5\% (Faul et al., 2007; Fleiss et al., 2003). Such analyses would necessarily also need to be stratified by gender, allowing for oversampling of male nurses. One would probably also want to be able to account for alternative avenues of oppression (e.g., racialized minority group membership, immigration status and characteristics of place [rural and ED resourcefulness]) and to test the profession (nurse versus physician) by gender (female versus male) interaction. Such would require hundreds of participants in each of the eight study groups: requiring more than a thousand participants in a national study. Also, such surveys ought to be amply funded, allowing for the staffing and procedural supports needed to ensure high participation rates. Such national and international study, ultimately extending beyond North America will undoubtedly be quite expensive, but such an investment holds the promise of huge knowledge dividends. Such a commitment to advancing evidence-based understandings of the mental health challenges facing the women and men who work in one of our health care system's most crucial structures, emergency care, is probably the most important step we can take in planning their preventive and therapeutic mental health care.

Qualitative studies of key informing groups are also needed to identify potential risks attending the structures of North American emergency care that might be specifically associated with being a woman versus being a nurse, for example (Bowleg, 2012; de Smidt and Gorey, 1997; Hulko, 2009; Lundahl et al., 2009). Such research, perhaps in semi-structured interview formats, giving voice to the rich narratives of diverse people working in EDs could be very helpful in developing ideas about how to best prevent and or effectively intervene with ED personnel with serious mental health challenges such as PTSD. Intensive qualitative studies with small groups of female and male nurses and physicians could help us better understand not merely their unique vulnerabilities and risks, but also their unique resiliencies and protections. This knowledge could be instrumental in tailoring professionally and culturally competent mental health care for nurses and physicians, be they women or men working in emergency care.

Finally, for its admitted rapidity, this review is probably limited in another way. A bit more of its practical context may be illuminating. First, this synthesis was essentially unfunded. Second, all the worldwide research on PTSD among a continuum of first responders, pre- to hospital-based emergency, rescue and intensive care workers was first informally scoped (Ganann et al., 2010; Tricco et al., 2015, 2016). The voluminous results of those preliminary searches in addition to funding limits caused us to focus on a constrained review of the area with a glaring gap in the extant literature: PTSD among ED personnel in high income countries. Exhaustive searches were accomplished, but of focused questions within these noted constraints and emphasizing the experiences of nurses and women. These may be thought strengths of this review. However, one preferred systematic review method (PRISMA) was not adhered to (Moher et al., 2009). As two reviewers independently searched for eligible studies, informally sharing their developing methods throughout the process, a unified flow chart, detailing each step of the information gathering process was not produced. Recall though that study selection and analyses were cross validated by two reviewers. For these reasons this rapid systematic search is believed to approximate the validity of a full systematic review. Still, a better-endowed systematic review, accomplished by independent reviewers, would be welcome. Such systematic replications are the hallmark of sound scientific inquiry, primary and synthetic.

\section{Conclusions}

This research review synthesized the evidence on the prevalence of PTDS among ED clinical staff members in Canada and the USA. It estimated that one of every five such ED personnel in Canada and the USA met PTSD diagnostic criteria. This represents a major problem of great clinical and policy significance as such mental illness among emergency care providers probably detrimentally affects their personal lives and plausibly so affects the emergency care they provide. This synthesis also suggested that the prevalence of PTSD is perhaps two-fold greater among ED nurses than physicians, and that gender (being a woman) probably plays a significant role in the relatively greater risk of nurses. Better controlled, more powerful probability surveys, ideally, that examine the profession by gender interaction, are needed to affirm (or refute) these synthetic findings. Qualitative inquiries that tap into the key informing experiences of diverse ED personnel are also needed to best plan and implement their preventive and therapeutic care.

\section{Data availability}

All data analyzed in this study are cited in this article and available in the public domain.

Received: 29 June 2020; Accepted: 19 August 2020; Published online: 09 September 2020

\section{References}

Studies included in the rapid systematic review are noted with an asterisk.

Adriaenssens J, de Gucht V, Maes S (2012) The impact of traumatic events on emergency room nurses: findings from a questionnaire survey. Int J Nurs Stud 49(11):1411-1422. https://doi.org/10.1016/j.ijnurstu.2012.07.003 
*Alden LE, Regambal MJ, Laposa JM (2012) The effects of direct versus witnessed threat on emergency department healthcare workers: implications for PTSDCriterion A. J Anxiety Disord 22(8):1411-1422. https://doi.org/10.1016/j. janxdis.2008.01.013

American Medical Association (2019) Physician characteristics and distribution in the US. AMA Survey and Data Resources, Chicago

Berger W, Coutinho ESF, Figueira I et al. (2012) Rescuers at risk: a systematic review and meta-regression analysis of the worldwide current prevalence and correlates of PTSD in rescue workers. Soc Psychiatry Psychiatr Epidemiol 47 (6):1001-1011. https://doi.org/10.1007/s00127-011-0408-2

Bowleg L (2012) The problem with the phrase women and minorities: intersectionality-an important theoretical framework for public health. Am J Public Health 102(7):1267-1273. https://doi.org/10.2105/AJPH.2012.300750

Butun A, Linden M, Lynn F, McGaughey F (2019) Exploring parents' reasons for attending the emergency department for children with minor illnesses: a mixed methods systematic review. Emerg Med J 36:39-46. https://doi.org/ 10.1136/emermed-2017-207118

Canadian Institute for Health Information (2019a) Nursing in Canada, 2018. https://www.cihi.ca/en/nursing-in-canada-2018. Accessed 15 Mar 2020

Canadian Institute for Health Information (2019b) Physicians in Canada, 2018: summary report. https://www.cihi.ca/sites/default/files/document/physiciansin-canada-2018.pdf. Accessed 15 Mar 2020

Carleton RN, Afifi TO, Turner S et al. (2018) Mental disorder symptoms among public safety personnel in Canada. Can J Psychiatry 63(1):54-64. https://doi. org/10.1177/0706743717723825

Cheung KL, ten Klooster PM, Smit C, de Vries H, Pieterse ME (2017) The impact of non-response bias due to sampling in public health studies: a comparison of voluntary versus mandatory recruitment in a Dutch national survey on adolescent health. BMC Public Health 17:276. https://doi.org/10.1186/s12889-017-4189-8

Cooper H (2017) Research synthesis and meta-analysis: a step-by-step approach, 5th edn. Sage, Thousand Oaks, CA

Cooper H, Patall EA (2009) The relative benefits of meta-analysis conducted with individual participant data versus aggregated data. Psychol Method 14 (2):165-176. https://doi.org/10.1037/a0015565

Cottler LB, Ajinkya S, Merlo LJ, Nixon SJ, Abdallah AB, Gold MS (2013) Lifetime psychiatric and substance use disorders among impaired physicians in physicians health program: comparison to a general treatment population. J Addict Med 7(2):108-112. https://doi.org/10.1097/ADM.0b013e31827fadc9

Crilly J, Chaboyer W, Creedy D (2004) Violence towards emergency department nurses by patients. Accid Emerg Nurs 12(2):67-73. https://doi.org/10.1016/j. aaen.2003.11.003

*Czaja AS, Moss M, Mealer M (2012) Symptoms of posttraumatic stress disorder among pediatric acute care nurses. J Pediatr Nurs 27(4):357-365. https://doi. org/10.1016/j.pedn.2011.04.024

*DeLucia JA, Bitter C, Fitzgerald J, Greenberg M, Dalwari P, Buchanan P (2019) Prevalence of post-traumatic stress disorder in emergency physicians in the United States. West J Emerg Med 20(5):740-746. https://doi.org/10.5811/ westjem.2019.7.42671

de Smidt GA, Gorey KM (1997) Unpublished social work research: systematic replication of a recent meta-analysis of published intervention effectiveness research. Soc Work Serv 21(1):58-62. https://doi.org/10.1093/swr/21.1.58

Donnelly E, Siebert D (2009) Occupational risk factors in the emergency medical service. Prehosp Disaster Med 24(5):422-429. https://doi.org/10.1017/ S1049023X00007251

Faul F, Erdfelder E, Lang AG, Buchner A (2007) G*Power 3: a flexible statistical power analysis program for the social, behavioral, and biomedical sciences. Beh Res Methods 39(2):175-191. https://doi.org/10.3758/BF03193146

Fleiss JL, Levin B, Paik MC (2003) Statistical methods for rates and proportions, 3rd edn. John Wiley \& Sons, New York

Foa EB, McLean CP, Zang Y et al. (2016) Psychometric properties of the Posttraumatic Stress Disorder Symptom Scale Interview for DSM-5 (PSSI-5). Psychol Assess 28(10):1159-1165. https://doi.org/10.1037/pas0000259

Ganann R, Ciliska D, Thomas H (2010) Expediting systematic reviews: methods and implications of rapid reviews. Implemen Sci 5:56. https://doi.org/ 10.1186/1748-5908-5-56

${ }^{*}$ Gates DM, Gillespie GL, Succop P (2011) Violence against nurses and its impact on stress and productivity. Nurs Econ 29(2):59-67

Grenier AM, Gorey KM (1998) Effectiveness of social work with older people and their families: a meta-analysis of conference proceedings. Soc Work Res 22 (1):60-64. https://doi.org/10.1093/swr/22.1.60

Hay K, McDougal L, Percival V et al. (2019) Disrupting gender norms in health systems: making the case for change. Lancet 393(10190):2535-2549. https:// doi.org/10.1016/S0140-6736(19)30648-8

Hulko W (2009) The time- and context-contingent nature of intersectionality and interlocking oppressions. Affilia 24(1):44-55. https://doi.org/10.1177/0886109908326814

*Jackson TN, Morgan JP, Jackson DL et al. (2019) The crossroads of posttraumatic stress disorder and physician burnout: a national review of United States traumaand nontrauma surgeons. Am Surgeon 85(2):127-135
*Joseph B, Pandit V, Hadeed G et al. (2014) Unveiling posttraumatic stress disorder in trauma surgeons: a national survey. J Trauma Acute Care Surg 77 (1):148-154. https://doi.org/10.1097/TA.0000000000000271

Katsavouni F, Bebetsos E, Malliou P, Beneka A (2016) The relationship between burnout, PTSD symptoms and injuries in firefighters. Occup Med 66 (1):32-37. https://doi.org/10.1093/occmed/kqv144

Kerasiotis B, Motta RW (2004) Assessment of PTSD symptoms in emergency room, intensive care unit, and general floor nurses. Int J Emerg Ment Health 6(3):121-133

Kilpatrick DG, Resnick HS, Milanak ME, Miller MW, Keyes KM, Friedman MJ (2013) National estimates of exposure to traumatic events and PTSD prevalence using DSM-IV and DSM-5 criteria. J Trauma Stress 26(5):537-547. https://doi.org/10.1002/jts.21848

*Laposa JM, Alden LE (2003) Posttraumatic stress disorder in the emergency room: exploration of a cognitive model. Behav Res Ther 41(1):49-65. https:// doi.org/10.1016/S0005-7967(01)00123-1

*Lavoie S, Talbot LR, Mathieu L, Dallaire C, Dubois MF, Courcy F (2016) An exploration of factors associated with post-traumatic stress in ER nurses. J Nurs Manag 24(2):174-183. https://doi.org/10.1111/jonm.12294

*Luftman K, Aydelotte J, Rix K et al. (2017) PTSD in those who care for the injured. Injury 48(2):293-295. https://doi.org/10.1016/j.injury.2016.11.001

Lundahl B, Yaffe J, Hobson J (2009) Today's studies, tomorrow's meta-analyses: implications for evidence informed decision-making in social work. J Soc Serv Res 35(1):1-9. https://doi.org/10.1080/01488370802473807

Moher D, Liberati A, Tetzlaff J, Altman DG (2009) Preferred reporting items for systematic reviews and meta-analyses: the PRISMA statement. Br Med J 339: b2535. https://doi.org/10.1136/bmj.b2535

Morley C, Unwin M, Peterson GM, Stankovich J, Kinsman L (2018) Emergency department crowding: a systematic review of causes, consequences and solutions. PLoS ONE 13(8):e0203316. https://doi.org/10.1371/journal. pone. 0203316

Naushad VA, Bierens JJLM, Nishan KP et al. (2019) A systematic review of the impact of disaster on the mental health of medical responders. Prehosp Disaster Med 34(6):632-643. https://doi.org/10.1017/S1049023X19004874

Needham I, Abderhalden C, Halfens RJG, Fischer JE, Dassen T (2005) Nonsomatic effects of patient aggression on nurses: a systematic review. J Adv Nurs 49(3):283-296. https://doi.org/10.1111/j.1365-2648.2004.03286.x

Petrie K, Milligan-Saville J, Gayed A et al. (2018) Prevalence of PTSD and common mental disorders amongst ambulance personnel: a systematic review and meta-analysis. Soc Psychiatry Psychiatr Epidemiol 53:897-909. https://doi org/10.1007/s00127-018-1539-5

*Powell PA (1996) The prevalence of posttraumatic stress disorder among registered nurses working Manitoba emergency and intensive care units: a replication study. Master's thesis, ProQuest Dissertations Theses (304336197)

Prins A, Bovin MJ, Smolenski DJ et al. (2016) The primary care PTSD screen for DSM-5 (PC-PTSD-5): development and evaluation within a veteran primary care sample. J Gen Intern Med 31(10):1206-1211. https://doi.org/10.1007/ s11606-016-3703-5

Robertson N, Perry A (2010) Institutionally based health care workers' exposure to traumatogenic events: systematic review of PTSD presentation. J Trauma Stress 23(3):417-420. https://doi.org/10.1002/jts.20537

Ruitenburg M, Frings-Dresen M, Sluiter J (2012) The prevalence of common mental disorders among hospital physicians and their association with selfreported work ability: a cross-sectional study. BMC Health Serv Res 12:292. https://doi.org/10.1186/1472-6963-12-292

Schernhammer ES, Colditz GA (2004) Suicide rates among physicians: a quantitative and gender assessment (meta-analysis). Am J Psychiatry 161 (12):2295-2302. https://doi.org/10.1176/appi.ajp.161.12.2295

Schwab D, Napolitano N, Chevalier K, Pettorini-D’Amico S (2016) Hidden grief and lasting emotions in emergency department nurses. Creat Nurs 22 (4):249-253. https://doi.org/10.1891/1078-4535.22.4.249

Slatten LA, Carson DK, Carson PP (2011) Compassion fatigue and burnout: what managers should know. Health Care Manag 30(4):325-333. https://doi.org/ 10.1097/HCM.0b013e31823511f7

Tolin DF, Foa EB (2008) Sex differences in trauma and posttraumatic stress disorder: a quantitative review of 25 years of research. Psychol Trauma S (1):37-85. https://doi.org/10.1037/1942-9681.S.1.37

Tricco AC, Antony J, Zarin W et al. (2015) A scoping review of rapid review methods. BMC Med 13:224. https://doi.org/10.1186/s12916-015-0465-6

Tricco AC, Lillie E, Zarin W (2016) A scoping review on the conduct and reporting of scoping reviews. BMC Med Res Methodol 6:15-24. https://doi.org/ 10.1186/s12874-016-0116-4

U.S. Bureau of Labor Statistics, Department of Labor (2019) Occupational outlook handbook: registered nurses. https://www.bls.gov/ooh/healthcare/registerednurses.htm. Accessed 15 Mar 2020

van Ameringen M, Mancini C, Patterson B, Boyle MH (2008) Post-traumatic stress disorder in Canada. CNS Neurosci Ther 14(3):171-181. https://doi.org/ 10.1111/j.1755-5949.2008.00049.x 
van Bogaert P, Clarke S, Wouters K, Franck E, Willems R, Mondelaers M (2013) Impacts of unit-level nurse practice environment, workload and burnout on nurse-reported outcomes in psychiatric hospitals: a multilevel modelling approach. Int J Nurs Stud 50(3):357-365. https://doi.org/10.1016/j.ijnurstu.2012.05.006

Weiss DS (2007) The impact of event scale: revised. In: Wilson JJ, Tang CS (eds) Cross-cultural assessment of psychological trauma and PTSD. Springer, New York, pp. 219-238

Wilkins KC, Lang AJ, Norman SB (2011) Synthesis of the psychometric properties of the PTSD checklist (PCL) military, civilian, and specific versions. Depress Anxiety 28(7):596-606. https://doi.org/10.1002/da.20837

\section{Competing interests}

The authors declare no competing interests.

\section{Additional information}

Correspondence and requests for materials should be addressed to D.I.N.T.

Reprints and permission information is available at http://www.nature.com/reprints
Publisher's note Springer Nature remains neutral with regard to jurisdictional claims in published maps and institutional affiliations.

\begin{abstract}
(c) (1)
Open Access This article is licensed under a Creative Commons Attribution 4.0 International License, which permits use, sharing, adaptation, distribution and reproduction in any medium or format, as long as you give appropriate credit to the original author(s) and the source, provide a link to the Creative Commons license, and indicate if changes were made. The images or other third party material in this article are included in the article's Creative Commons license, unless indicated otherwise in a credit line to the material. If material is not included in the article's Creative Commons license and your intended use is not permitted by statutory regulation or exceeds the permitted use, you will need to obtain permission directly from the copyright holder. To view a copy of this license, visit http://creativecommons.org/ licenses/by/4.0/
\end{abstract}

(C) The Author(s) 2020 